University of Nebraska - Lincoln

DigitalCommons@University of Nebraska - Lincoln

Faculty Publications, Department of Child, Youth, and Family Studies

Child, Youth, and Family Studies, Department of

2008

\title{
Prosocial Behaviors in Context: Examining the Role of Children's Social Companions
}

\author{
Maria Rosario de Guzman \\ University of Nebraska-Lincoln, mguzman2@unl.edu \\ Gustavo Carlo \\ University of Nebraska-Lincoln, carlog@missouri.edu \\ Carolyn P. Edwards \\ University of Nebraska-Lincoln, cedwards1@unl.edu
}

Follow this and additional works at: https://digitalcommons.unl.edu/famconfacpub

Part of the Family, Life Course, and Society Commons

de Guzman, Maria Rosario; Carlo, Gustavo; and Edwards, Carolyn P., "Prosocial Behaviors in Context: Examining the Role of Children's Social Companions" (2008). Faculty Publications, Department of Child, Youth, and Family Studies. 65.

https://digitalcommons.unl.edu/famconfacpub/65

This Article is brought to you for free and open access by the Child, Youth, and Family Studies, Department of at DigitalCommons@University of Nebraska - Lincoln. It has been accepted for inclusion in Faculty Publications, Department of Child, Youth, and Family Studies by an authorized administrator of DigitalCommons@University of Nebraska - Lincoln. 


\title{
Prosocial behaviors in context: Examining the role of children's social companions
}

\author{
Maria Rosario T. de Guzman, Gustavo Carlo, and Carolyn Pope Edwards \\ University of Nebraska-Lincoln, USA
}

\begin{abstract}
This study examines the role of immediate social companions in the prosocial behaviors of children from two cultural communities from the USA and the Philippines. Materials for this study comprised behavioral observations drawn from the Six Cultures Study - with 612 five-minute observations of 23 children (12 girls, 11 boys) from Orchard Town, MA, and 570 observations of 24 children (12 girls, 12 boys) from Tarong, Philippines, ranging in age from 3 to 11 years. Data were coded for instances of prosocial behaviors, as well as characteristics of social companions (age and relationship to actor). Results revealed several interesting findings. First, frequency of children's behaviors varied as a function of the age of their social companions. Children generally directed the highest number of prosocial behaviors towards infants and toddlers, except for younger children's prosocial behaviors towards relatives which were directed mostly towards adults. Second, frequency of prosocial behaviors varied as a function of kinship, but differently for the community groups. Tarong children were generally more prosocial towards relatives, while Orchard Town children showed more prosocial behaviors towards non-relatives. Results highlight the role of immediate contexts in prosocial behaviors of children, and the value of using cross-cultural methodology to examine contextual factors in developmental processes.
\end{abstract}

Keywords: context; culture; prosocial behavior

Prosocial behaviors are acts that are intended to benefit others (Eisenberg, 1986). In most societies, these behaviors are highly valued and are markers of competency in children. Nonetheless, empirical evidence suggests cultural diversity in children's performance of these acts (for review, see, Eisenberg, Fabes, \& Spinard, 2006), and while group differences have been linked to distal and societal level variables such as ethnicity (Knight, Cota, \& Bernal, 1993), or individualism-collectivism (Suzuki \& Greenfield, 2002), the more immediate proximal processes that could help explain why group differences emerge remain unexamined.

Understanding cultural differences in children's behaviors can best be understood in light of the child's evolving inter- actions with and within their immediate environments (Farver, 1999; Super \& Harkness, 1999, 2002). Culture is manifested in the organization of those immediate contexts, and as such it is in children's regular participation in those everyday settings and with regular companions that cultural competencies and expected behaviors are socialized (Super \& Harkness, 2002).

For prosocial behaviors, everyday contexts are important venues through which youth learn to respond to others' needs (Eisenberg, 2004). For example, when placed in situations that draw prosocial responding (e.g., infant-care), and when directed by others, children can learn to respond to others in a prosocial manner; and to practice their prosocial behaviors (de Guzman, Edwards, \& Carlo, 2005; Eisenberg, 2004).

Within contexts, social companions are especially important in children's prosocial responding (Edwards, 1993). Companions of varying age, kinship, and capabilities represent different opportunities for interactions and can shape children's behavioral tendencies over time. Because opportunities for interacting with particular companions vary considerably across cultures in ways often consistent with the socio-ecological milieu in which the child is embedded (Larson \& Verma, 1999; Tietjen, 1994), examining social companions provides an excellent opportunity to investigate the proximal processes surrounding group differences in behaviors.

Age of companions appears to be particularly relevant for children's prosocial responding. For example, in the company of infants, children display increased levels of nurturance, possibly due to the fact that infants are relatively helpless and need constant care (Braten, 1996; Edwards, 1986). Infant crying elicits empathic responding and prosocial behaviors, even among very young children (Fabes, Eisenberg, Karbon, Troyer, \& Switzer, 1994; Zahn-Waxler, Friedman, \& Cummings, 1983). By contrast, caring for toddlers seems to bring out more prosocial dominant behaviors (i.e., attempts to change another's behavior for that person's benefit) because of their increased independence, mobility, and demandingness and thus the corresponding need to limit, socialize, and keep the child safe (de Guzman et al., 2005; Whiting, 1983).

In experimental studies, adult presence has been linked to a suppression of sociable behaviors and an increase in aggressive tendencies (Barton, Olszewski, \& Madsen, 1979; Besevegis \& Lore, 1983). In those studies, however, adults did not interact with children in ways that facilitated prosocial actions. In everyday settings, adults can encourage children and communicate prosocial expectations. For example, rural Filipino children have been found to be prosocial towards younger siblings particularly as a result of adult direction (Jocano, 1969).

Correspondence - Maria Rosario T. de Guzman, Department of Child, Youth, \& Family Studies, 256 Mabel Lee Hall, University of Nebraska-Lincoln, Lincoln, NE 68588-0236, USA; e-mail: mguzman2@unl.edu

Data for this study were used with the permission of the Human Relations Area Files at Yale University under the auspices of Carol and Melvin Ember. We thank the families of Tarong, Philippines, and Orchard Town, MA, and the research collaborators and apprentices who participated in the collection of the behavior observations. This paper is based on the doctoral dissertation by Maria de Guzman. 
Kinship and social relationships are also important contextual factors that can impact upon prosocial action. For example, children self-report that they are more likely to act in a prosocial manner towards their parents and close friends, than towards siblings, teachers, and peers (Bigelow, Tesson, \& Lewko, 1992). Among relatives, children and adolescents report higher prosocial tendencies towards those with whom they are more closely related (Eisenberg, 1983; Webster, 2003). These findings are mirrored by behavioral observations of children in classrooms and experimental settings that show more prosocial responding towards relatives (Knight \& Chao, 1991), and towards friends rather than acquaintances (Birch \& Billman, 1986).

Finally, while contexts and companions impact children's behaviors, individual proclivities naturally exert their influence and interact with context effects on prosocial responding (de Guzman et al., 2005). Children's experiences and complexity of interactions change with age. As children grow older, they are increasingly able to select their own activities, they have access to a broader range of contexts and companions, and they are more able to selectively accept socializing agents' influences (Edwards, de Guzman, Brown, \& Kumru, 2006). Thus, examining children's prosocial behaviors in light of their immediate social companions, benefits from considering individual level variables such as age.

\section{The current study: Tarong and Orchard Town}

The goal of this study is to examine children's prosocial behaviors in natural settings, as a function of the characteristics of their social companions. This study examines these issues in two cultural communities both to increase the range of variability in access to companions, and to shed light on the role of social context in the emergent differences in prosocial behaviors of children from various communities. This study is a re-analysis of U.S. and Philippine children's behavioral observations drawn from the Six Cultures Study (B. B. Whiting \& Whiting, 1975). Materials were originally collected to examine the relations between child-rearing practices and children's personality development and behaviors, both across and within cultures. These data are described in detail in various publications (Whiting \& Edwards, 1988; B. B. Whiting \& Whiting, 1975).

Observational data were collected to represent the typical daily life of children. Children were observed in a wide range of contexts (e.g., school, home, church), which is in contrast to the single settings (e.g., classroom) more typical of observational studies. The unique nature of this data set makes it particularly useful for studying the issues posed in this study as the broader range of contexts represented also translates to a wider range of social companions.

The Philippine and U.S. data are particularly interesting to compare because of the many shared characteristics of the countries, as well as the marked differences in childhood experiences that are relevant to prosocial behaviors. For example, both countries are sovereign nations with democratic, capitalist governments. As the data were collected approximately 10 years after the Philippines gained independence from the USA, the educational system (and thus children's schooling) at that time was patterned on and thus similar to that established in the USA.

At the same time, both western and local Philippine researchers emphasize differences in Philippine and U.S. children's early experiences that are relevant to the study of positive so- cial behaviors and their social companions. Philippine society has been described as having a group-orientation with an emphasis on interdependence among family members (Enriquez, 1992). This is in contrast to independence expectations that are generally espoused by mothers, for example, in the USA (Bornstein, Tamis-LeMonda, \& Tal, 1992; Edwards, Knoche, Aukrust, Kumru, \& Kim, 2003). Orientations towards interdependence and dependence have been implicated in the development of prosocial tendencies (Eisenberg et al., 2006), and moreover, might be reflected in the everyday contexts of children. For example, the heavy emphasis on kinship ties in the Philippines is reflected in the composition of many households which often include extended families (Andres \& Ilada-Andres, 1987). Filipino children's daily companions, especially in rural areas, often include a conglomeration of individuals including immediate and extended family. Taken together, these earlier findings suggest that the social contexts often available to Philippine and U.S. children vary considerably - with Philippine children often among larger social networks which more often consist of extended family members. U.S. children are more often in contexts with peers rather than family members.

In short, the Philippines and the USA, while having some sociopolitical similarities, differ considerably in ways relevant to the social networks and socialization experiences of children. As such, contrasting patterns of prosocial behaviors in relation to social networks of children from those two countries can be anticipated.

While the limited related literature makes it difficult to draw firm predictions, some general hypotheses can be made about prosocial behavior patterns displayed by the children in this study. First, children are expected to show more prosocial behaviors towards babies, toddlers, and adults, compared with other children or their peers. This is consistent with earlier research suggesting that infants elicit nurturance and toddlers elicit prosocial dominance in others. Moreover, because adults are able to direct children's behaviors and thus ask them to conduct prosocial acts, children are also expected to show a high number of prosocial behaviors towards them, and thus least towards peers who are of more equal status to the actors.

Second, consistent with prior research on kinship and prosocial behaviors, children from communities in both the Philippines and the USA are expected to show more prosocial behaviors towards relatives than non-relatives. Given the strong socialization pressures for Filipino children to be prosocial towards their relatives in contrast to the socialization for independence in many communities in the USA, and the accompanying strong adult expectations for more generalized frequent prosocial behaviors within the family (Edwards, Kumru, de Guzman, Ha, Brown, \& Carlo, 2007), it is further hypothesized that the pattern favoring prosocial behaviors towards relatives will be stronger for Filipino children than for U.S. children.

Third, context differences (i.e., as a function of companions' age and kinship relation) are expected to interact with the child's age. While children generally become more competent with age and are more able to assess and respond to the needs of others, children are more able to exhibit individual proclivities and to selectively accept or deflect socialization pressures (Edwards et al., 2006). Older children are also more aware of social expectations for prosocial behaviors. As such, cultural community differences are expected to be more pronounced among older children. 


\section{Methods}

\section{Participants and materials}

Materials for this study consist of behavioral observations of children from the Philippines and the USA, both drawn from the larger data set of the Six Cultures Study (B. B. Whiting \& Whiting, 1975). In collecting the original data, pairs of researchers (husband and wife teams) took residence in their assigned communities for one year and collaborated with local investigators who were familiar with the language or dialect and the nuances of children's behaviors in those sites (see Whiting et al., 1966, for detailed descriptions).

The U.S. data were collected from Orchard Town (pseudonym), Massachusetts, which at the time of data collection, had a population of about 6,000. North Town, from which the sample was drawn, had about 1,000 inhabitants. The Orchard Town children came mainly from middle class families, with half the parents having a high school degree $(50 \%$ of mothers, $53 \%$ of fathers). The rest either had vocational/college degrees (33\% of mothers, $42 \%$ of fathers), graduate training (11\% of fathers), or some high school training ( $6 \%$ of mothers, and $5 \%$ of fathers).

The Philippine data were collected from Tarong (pseudonym), which is located in the northern province of Ilocos. Tarong is a rural barrio (today referred to in the Philippines as a "barangay"), or the smallest local unit of government. At the time of data collection, 61 families resided in the area, with a total population of 259. Most families in this barrio raised their own food. The majority of parents had some grade school education (51\% of fathers, $70 \%$ mothers), some finished grade school (4\% fathers), some attended or finished high school $(4 \%$ fathers, $12 \%$ mothers), or finished post high school education (17\% fathers, $4 \%$ mothers).

Family samples within each community were chosen to reflect groups who were familiar with each other, such as neighbors and/or relatives who participated in shared community activities like church or school events. In sampling children's behaviors, investigators attempted to represent periods of the day wherein "typical" activities occurred, and avoided sampling activities that occurred infrequently. To maximize observations of behaviors and interactions with others, hours of the day when the child was sleeping or inactive were avoided. Thus, while sampling of activities was not random, it was intended to be representative (Whiting et al., 1966).

During observations, all activities, verbalizations, and companions were recorded. People proximally present but not interacting with the child, the settings, and ongoing activities (e.g., play) were also recorded. Methodology and sampling were held constant across countries in order to facilitate crosscultural comparisons. Data-collection procedures are outlined in the field team guides (Whiting et al., 1966); and detailed characteristics of Orchard Town and Tarong are elaborated in Fischer and Fischer (1966) and Nydegger and Nydegger (1966) respectively.

The Orchard Town data consist of 612 observations of 23 children (12 girls, 11 boys), ages $4-11$ years $(M=6.86, S D=$ 2.50). The Tarong data consist of 570 behavioral observations of 24 children (12 girls, 12 boys), ages $3-10$ years $(M=5.90, S D$ $=2.10)$. Each child was observed between 13 and 39 times $(M=$ $23.34, S D=7.03)$. These data were divided into two age groups - "Younger children," or those where the focal child was aged 3-5 (11 Tarong, 10 Orchard Town children) and approximated the preschool age; and "Older children," or those where the focal child was aged 6-10 (13 Tarong, 13 Orchard Town children), who approximated the elementary age. Note that research teams collected data independently, and this resulted in different numbers of observations per focal child; in Tarong there were more observations per child than in Orchard Town.

\section{Coding categories}

Prosocial behaviors. Because data were collected from naturalistic settings and without experimental manipulations, it was anticipated that prosocial acts would not be as frequent as is the case in laboratory settings where the range of behaviors is restricted to increase the probability of prosocial choice. Thus, a broad definition of prosocial behaviors was utilized to capture as many prosocial acts as possible. Prosocial acts coded were drawn from the few existing naturalistic studies on pro- social behaviors (Abramovitch, Corter, Pepler, \& Stanhope, 1986; Iannotti, 1985; Whiting, 1983; Whiting \& Whiting, 1975), and included instances of sharing, helping, comforting, verbal prosociality (e.g., encouraging, supporting, granting permission), and prosocial dominance (i.e., attempts to control another's behavior for that person's benefit). Prosocial acts per observation ranged from 0 to 12 for Orchard Town children $(M=.81, S D=1.75)$ and from 0 to 10 for Tarong children $(M=.93, S D=1.53)$.

Characteristics of companions. Information on companions' ages and relationship to the target child were mostly available from the census data provided with the observations. Age of companions was divided into three categories, namely, young children (infants and toddlers, 1-5 years), older children (6-10 years) and adults (16 years and up). Kinship was coded as either "close relatives" (siblings, parents, grandparents and parents) or "non-relatives." Because information on the degree of relatedness for child companions was not always clear (e.g., friend or cousin), only siblings and half-siblings were coded as close relatives when the companion was another child.

\section{Coding procedures}

Training for coding was carried out by initially discussing the coding instructions, allowing coders (four undergraduates) to read 20 randomly chosen observations from the two communities. Those observations were then coded and compared against the researcher's own coding. Differences and questions were discussed and adjustments were made to the coding directions. This process was repeated until $90 \%$ agreement was achieved. Spot inter-rater reliability checks were conducted throughout the actual coding with 21\% (242) of the randomly selected observations. Coders scored between 30 and 66 observations for inter-rater tests. Inter-rater agreement on identifying prosocial behaviors was 96.83\% (Cohen's kappa $=.93)$.

\section{Results}

To correct for differential opportunities that Orchard Town and Tarong children had to display prosocial behaviors towards particular companions (Figure 1), frequency scores were converted to proportion prosocial scores. This was computed by dividing frequency scores by the percentage of observations 


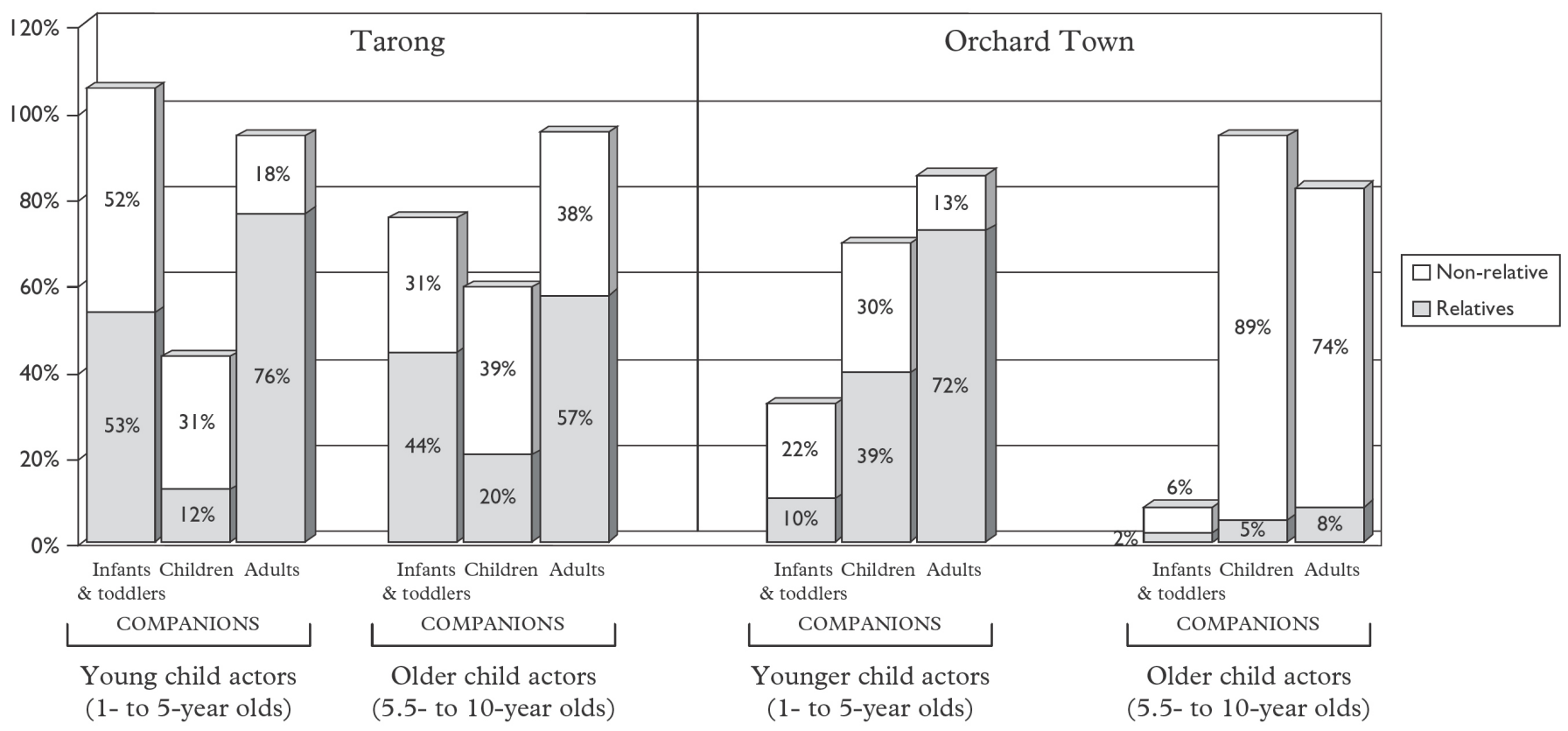

Figure 1. Percentage of younger and older Orchard Town and Tarong children's observations wherein infant/toddler, children, and adult companions were present. Percentages indicate presence of at least one person in that category during the five-minute observation; and categories are not mutually exclusive, thus totals can exceed $100 \%$.

where companions were present. Thus, if a child directed five prosocial acts towards adults, and adults were in $50 \%$ of her observations, that child gets a proportion score of $(10 / .5=) 20$. If adults were only in $25 \%$ of her observations, the score would be $(10 / .25=) 40$.

Mixed groups analyses of variance (ANOVA) were conducted to examine Community ( 2 between-group levels: Orchard Town, Tarong) $\times$ Kinship (2 within-group levels: relatives; non-relatives) $\times$ Actor Age (2 between-group levels: 3-5 years; 5-11 years) $\times$ Companion Age (3 within-group levels: young children, older children, adults) differences in prosocial acts. Pair-wise analyses were conducted with Bonferroni's comparisons $(p<.05)$. (See Table 1 for descriptive statistics.)

A main effect emerged for Community, $F(1,1178)=9.87$, $M S e=36.16, p<.001$, subsumed by interactions of Kinship $\times$ Community, $F(1,1178)=39.25$, MSe $=7.85, p<.001$; and Community $\times$ Companion Age, $F(1,2356)=3.91, M S e=15.25, p<$ .02. In addition, interactions of Companion Age $\times$ Actor Age, $F(1,2356)=19.24, M S e=15.25, p<.01$; and Kinship $\times$ Companion Age, $F(2,2356)=13.87, M S e=28.57, p<.001$ were found, subsumed by three-way Companion Age $\times$ Community $\times$ Actor Age, $F(2,2356)=64.56, M S e=4.23, p<.01$; and Kinship $\times$ Companion Age $\times$ Actor Age interactions, $F(2,2356)=16.26, M S e=$ $28.57, p<.01$. These were further subsumed by a four-way Kinship $\times$ Companion Age $\times$ Actor Age $\times$ Community interaction, $F(2,2356)=5.14, M S e=28.57, p<.01$. This interaction was followed up by actor age.

\section{Younger children}

For younger children (3-5-year olds), a significant effect was found for Age of Companion, $F(1,528)=13.05$, MSe $=10.22$, $p<.01$, with prosocial acts towards young children (infants/ toddlers $)(M=1.63, S D=6.43)$ more frequent compared with adults $(M=.77, S D=2.17)$ and older children $(M=.59, S D=$ 1.99). There was also a Kinship $\times$ Age of Companion interaction, $F(2,1056)=1.14, M S e=9.39, p<.001$, followed-up separately by Kinship.

For relatives, there was an effect of Companion Age, $F(2$, $1060)=27.36, M S e=11.94, p<.01$, with prosocial acts towards adults $(M=1.64, S D=5.77)$ more frequent compared with all others; and behaviors towards young children $(M=.44, S D=$ 1.36) more frequent than towards older children $(M=.17, S D=$ 1.36). Similarly for non- relatives, there was an effect of Companion Age, $F(2,1056)=5.96, M S e=7.56, p<.01$, with pair-wise comparison indicating that prosocial acts to young children $(M$ $=.86, S D=4.30)$ were more frequent than to older children $(M$ $=.38, S D=1.52)$ and adults $(M=.32, S D=1.48)$. These findings are illustrated in Figure 2.

As well, there was a Kinship $\times$ Community interaction, $F(2$, $528)=7.23, M S e=10.02, p<.01$. Follow-ups of this interaction showed a simple effect only for the Orchard Town children, $F(1,232)=23.17, M S e=25.35, p<.01$, who showed more prosocial behaviors towards relatives than non-relatives. These patterns are illustrated in Figure 3.

\section{Older children}

A main effect was found for Companion Age, $F(2,1300)=$ $10.18, M S e=9.33, p<.01$; and Community, $F(1,650)=4.43$, MSe $=58.86, p<.04$. These were subsumed by interactions of Kinship $\times$ Community, $F(2,650)=46.05, M S e=6.09, p<.01$; Age of Companion $\times$ Community, $F(2,1300)=5.96, M S e=6.41, p<.01$; and Age of Companion $\times$ Kinship, $F(2,1300)=5.19, M S e=44.14$, $p<.01$. These were subsumed by a three-way interaction of Kinship $\times$ Community $\times$ Age of Companion, $F(2,1300)=4.79$, MSe $=44.14, p<.01$. This interaction was followed up separately by Community. 


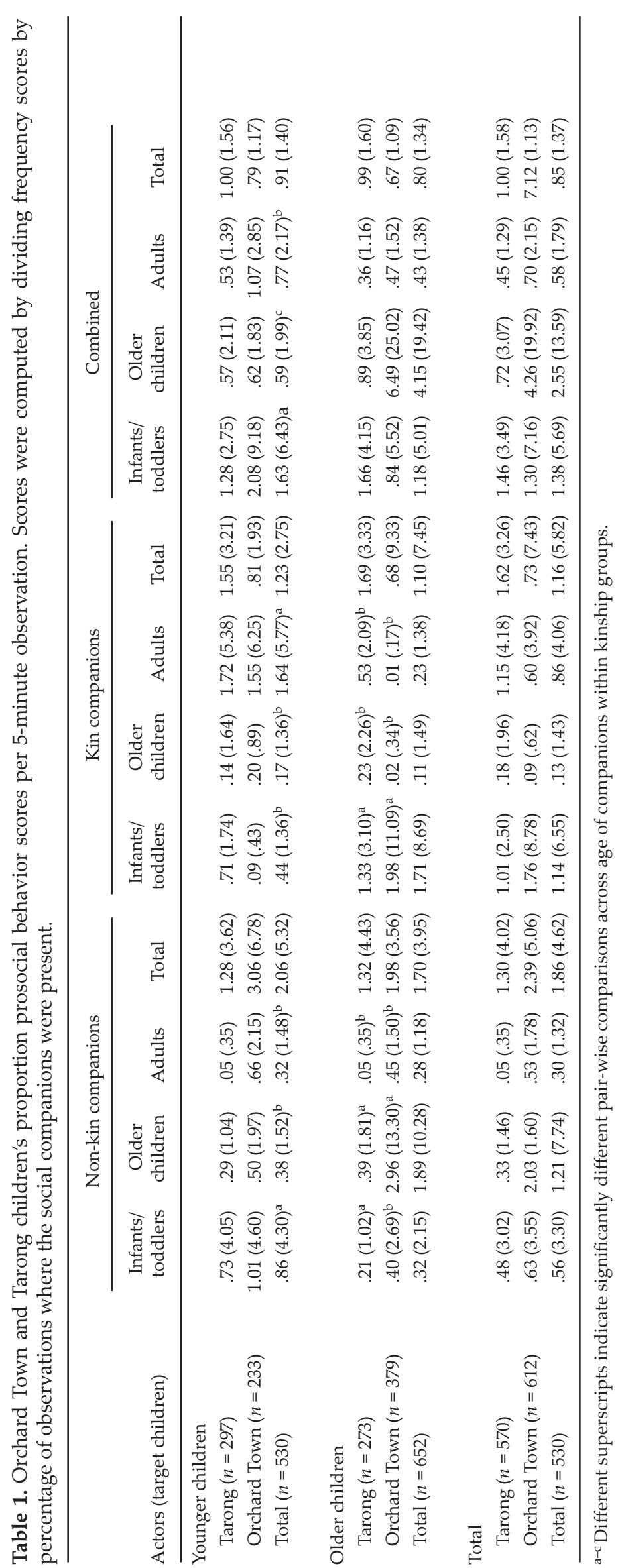




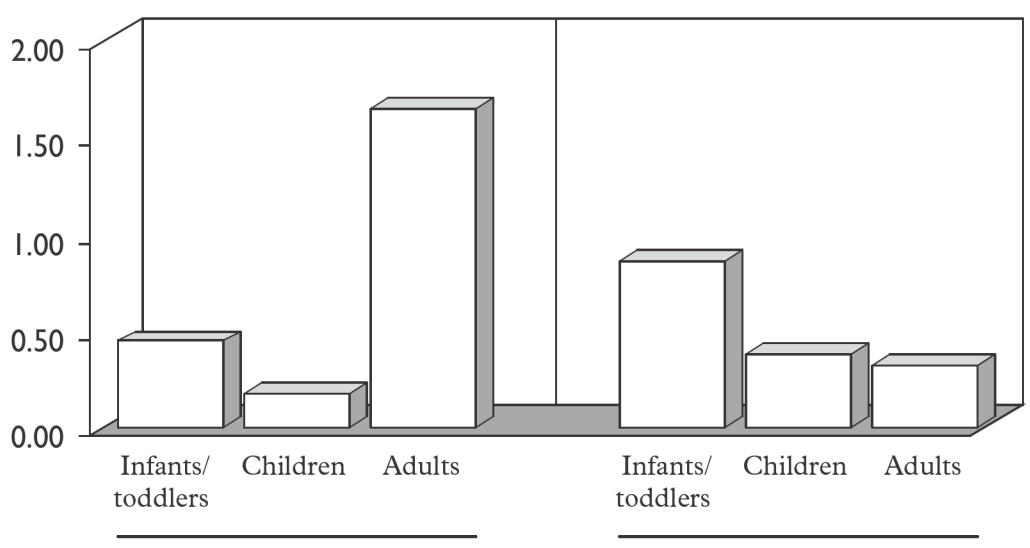

Relatives

Non-relatives

Figure 2. Frequency of prosocial behaviors in young children's observations as a function of companion age and kinship relationship (figures represent average number of prosocial acts per five-minute observation).

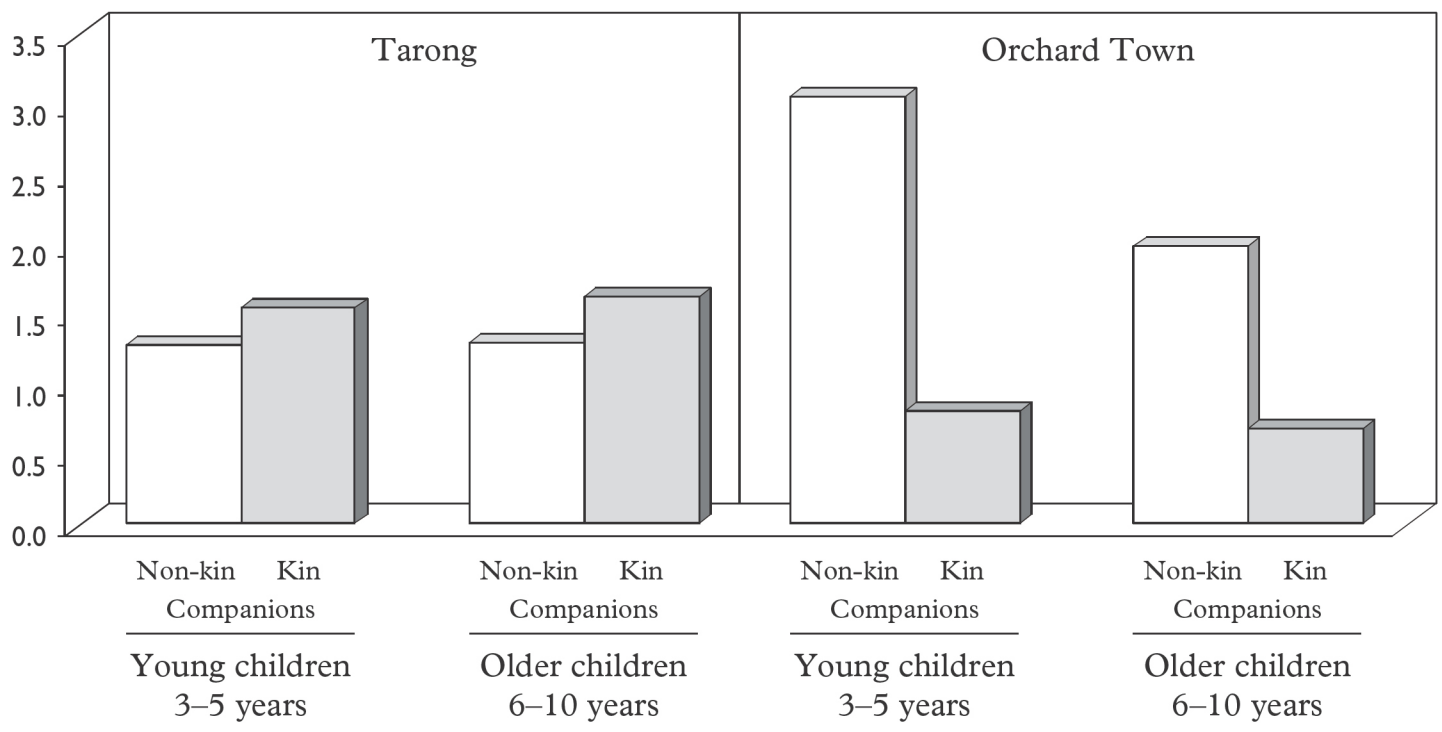

Figure 3. Frequency of prosocial behaviors towards kin and non-kin companions, presented separately by cultural community and age of actor (figures represent average number of prosocial acts per 5-minute observation).

Older Tarong children. Main effects were found for Kinship, $F(1,272)=40.76, M S e=2.36, p<.01$, and Companion Age, $F(2$, $544)=9.09, M S e=4.40, p<.01$, both subsumed by an interaction of Kinship $\times$ Companion Age, F $(2,544)=16.21$, MSe $=3.54, p<$ .01 . Simple effects test of this interaction were conducted separately by kinship.

For relatives, there was an effect of Companion Age, $F(2$, $544)=13.63, M S e=6.46, p<.01$, with prosocial acts directed to young children $(M=1.33, S D=3.10)$ more frequent compared with adults $(M=.53, S D=2.09)$ and older children $(M=.23$, $S D=2.26)$. For non-relatives, there was an effect of Companion Age, $F(2,544)=5.58, M S e=1.38, p<.01$, with more prosocial acts directed towards young children $(M=.21, S D=1.02)$ and older children $(M=.39, S D=1.81)$ than towards adults $(M=.05$, $S D=.35)$. (See Figure 4)

Older Orchard Town children. Main effects were found for Kinship, $F(1,378)=23.37, M S e=8.77, p<.01$, and Companion Age, $F(2,756)=10.89, M S e=30.07, p<.01$, both subsumed by a Kinship $\times$ Companion Age interaction, $F(2,756)=13.29$, MSe
$=73.43, p<.01$. Simple effects test of this interaction were conducted separately by kinship. For behaviors towards relatives, there was an effect of Companion Age, $F(2,756)=11.86$, MSe = $41.09, p<.01$, with prosocial acts to young children $(M=1.98$, $S D=11.09)$ significantly higher than to adults $(M=.01, S D=.17)$ and older children $(M=.02, S D=.34)$. For non-relatives, there was a significant effect of Companion Age, $F(2,756)=13.08$, $M S e=62.41, p<.01$, with acts to older children $(M=1.89, S D=$ $10.28)$ significantly more frequent than to adults $(M=.53, S D=$ $1.78)$ and young children $(M=.32, S D=2.15)$.

In summary, in behavioral observations of young (3-5-yearold) children, prosocial behaviors were directed mostly towards adults (in the case of relatives) and infants/toddlers (in the case of non-relatives) (Figure 2). Moreover, observations of young Orchard Town children showed that children directed more prosocial behaviors towards non-relatives than relatives, while no kinship differences were found in observations of young Tarong children (Figure 3).

More differentiations were found in the observations of 


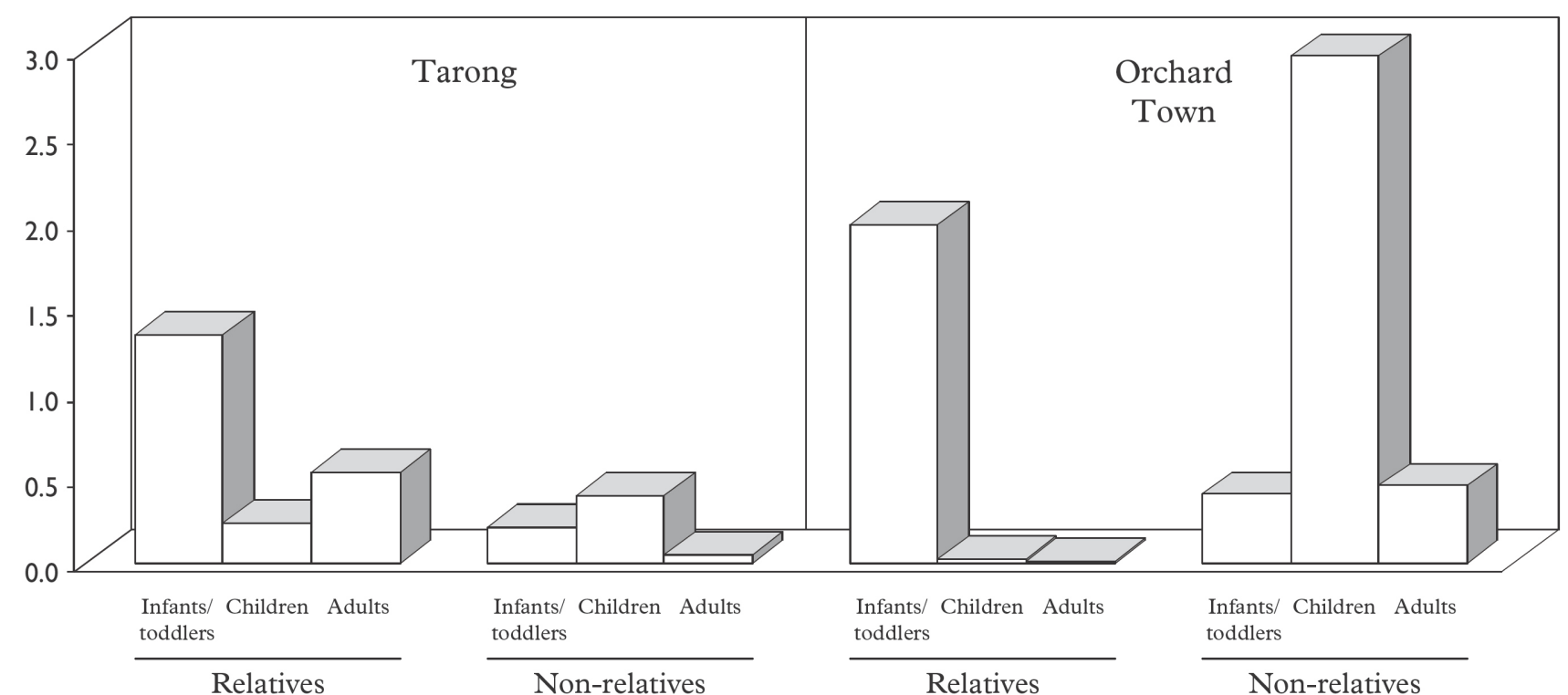

Figure 4. Frequency of prosocial behavior in older children's observations as a function of kinship relationship, presented separately by cultural community and age of companion (figures represent average number of prosocial acts per five-minute observation).

older (6-10-year-old) children. Among older Tarong children, most prosocial behaviors towards relatives were directed to young children (infants/toddlers), while most prosocial behaviors towards non-relatives were directed to young children and adults and least to other children. In observations of older Orchard Town children, prosocial behaviors towards relatives were directed mostly towards infants (similar to Tarong children), but prosocial behaviors towards non-relatives were directed mostly towards other children (Figure 4).

\section{Discussion}

Children are socialized within broad cultural contexts that are reflected in the organization of their everyday activities and the social settings they frequent. Within these immediate environments, children interact with regular companions who, by their very characteristics, can provide opportunities for performing various behaviors, including those prosocial in nature. This study examined the role of immediate context variables, particularly the characteristics of social companions, in Philippine and U.S. children's performance of prosocial acts in naturalistic settings.

Results revealed several interesting findings. First, consistent with the first hypothesis, companions' age emerged as an important correlate of prosocial responding - with children, regardless of cultural community, generally displaying pro- social behaviors most frequently towards infants/toddlers and adults. Nurturance towards young children has been well documented, which researchers have attributed to infants' obvious helplessness and need for constant supervision, as well as to the eliciting power of their appearance, smiles, coos and other signals. B. B. Whiting and Whiting (1975) found that in rural, traditional communities, older children are assigned childcare duties and are expected to help care for younger siblings. This study goes beyond that to find that when opportunities for prosocial action are accounted for, children in general, including those from the Orchard Town sample, actually display high levels of prosociality towards younger children. The following observation illustrates a Tarong child showing affection for an infant sibling despite protests from her mother.

Zosima (female, age 5) is sitting with her mother. Her baby brother is sleeping in a hammock. Zosima wanders, then looks into the hammock where some flies had settled on the baby's face and starts waving the flies away. She complains that mother should not have taken the mosquito net away. Her mother laughs a little. Zosima continues to wave at the flies. Her mother hushes her (signaling to stop). Zosima straddles the baby and kisses him on the forehead. Her mother taps her on her bottom, telling her not to bother the baby.

In addition, children might also be aware of cultural expectations for nurturance towards younger siblings. For example, the following observation from Tarong shows parents clearly communicating expectations for sharing with an infant sibling.

Ricardo (male, 4) walks into the kitchen holding a smoked fish. His infant brother Froilan is sitting in a chair, and their parents are both present. They laugh at the sight of Ricardo carrying a fish and they comment (teasingly) that maybe he would not even share it with Froilan. Upon hearing this, Ricardo breaks off the fish head and gives it to Froilan. He continues to eat and stops when there is very little fish left. He looks at whether his brother still has any fish left, and then breaks what is left of his and gives half to his brother.

Results also suggest that adults were often the target of prosocial behaviors, particularly in younger children's pro- social acts towards relatives. This is not surprising as adults' social status in relation to children allows them to assign tasks, relegate chores, and make suggestions for children to act in a prosocial manner. Young children, especially, who are more often in the presence of adult relatives (Figure 1), are more likely to be under their direction. For example, the following observa- 
tion depicts an adult's ability to direct children to participate in productive activities, even if they do not want to. This observation is drawn from the U.S. sample.

Susy (female, 10) is sorting laundry with her mother Stella. She is putting socks together in pairs, looking far away. She looks as if she had just finished crying. Stella asks, "Susy, go heat Mrs. Fischer (observer) a cup of coffee." Susy goes silently into the kitchen. While she is away, the mother tells the observer, "I told the kids to clean up the house. Susy is mad because she has to sort clothes and she wants to go over and play with Caroline." Susy returns with the coffee and hands it to the observer. Susy is silent during the whole observation. Observer notes, "The silence is aggressive."

Interestingly, older Orchard Town children showed a high level of prosocial responding towards their non-kin peers. While scores were controlled for availability of social companions, this pattern is consistent with the high number of observations in which Orchard Town children were in the presence of non-kin peers. Orchard Town children spend considerable amounts of time in contexts with friends, classmates and peers in other activities (e.g., Brownies, Sunday school, play groups), as is displayed in Figure 1. It is likely that Orchard Town children are able to foster more significant relationships with their peers, resulting in an increased likelihood of showing prosocial behaviors towards non-relatives.

A second pattern found in this study is that prosocial behaviors varied as a function of the actor's kinship relation, partially supporting the second hypothesis. Orchard Town children directed more prosocial behaviors towards non-relatives, whereas the Tarong children directed more towards relatives. This pattern is consistent with other researchers' assertions that childhood in the Philippines emphasizes familial interdependence (Enriquez, 1992), while independence is emphasized in the USA (Bornstein et al., 1992; Knight et al., 1993), thus socializing children towards a more generalized pattern of prosocial responding (Edwards et al., 2007). Indeed these patterns are also consistent with the amount of time children in this study spent with relatives and non-relatives (Figure 1). It is possible that children are learning to display prosocial behaviors more towards social companions more often available in their everyday settings. Similar to the potential explanation posed for the effect of age of companions, it is possible that children develop more familiarity or a deeper relationship with those they spend more time with, and are thus more likely to display prosocial behaviors towards them.

Finally, as alluded to earlier, cultural and context differences were more pronounced for older, rather than younger children (third hypothesis). While certainly socialization experiences vary early on (Bornstein et al., 1992), it is often in later childhood that cultural scripts become more evident as greater degrees of cross-cultural variability emerge in children's access to activities, contexts and companions (Edwards et al., 2006). For example, older Tarong children spent considerably more time in contexts where relatives are present, compared with older Orchard Town children (Figure 1) who attend school and other activities (e.g., Brownies) involving peers and other non-relatives. These types of experiences provide opportunities for children to develop significant relationships with, and learn to be prosocial towards, non-kin companions. Thus, even when prosocial behavior scores were controlled for the availability of companions, Orchard Town and Tarong children learn to direct prosocial behaviors towards relatives and non-relatives differently, with these socialization differences emerging among the older age group.

\section{Implications and contributions}

The present study contributes to existing literature in three ways. First, it illustrates the importance of examining immediate context variables, especially children's companions, in helping to understand the socialization of cultural differences in prosocial behaviors. Cultural research on prosocial development has traditionally focused on differences in cultural values, such as values fostering competition and cooperation. The current approach focused on immediate processes and experiences and how these, interacting with personal variables such as age, might help explain both between- and within-group differences in children's behaviors.

Second, this study emphasizes the importance of cross- cultural research to uncover developmental processes that might be difficult to observe within a single society. Research on context and outcome behaviors benefits from cross-cultural methods to increase the range in the variables of interest. Because immediate environments are limited by geographical location and societal structure, it is important to broaden the sampling of cultures in which these variables are examined. For example, the Tarong children had limited access to contexts where no adult kin were present, while Orchard Town children had few opportunities to be in contexts with infants.

Moreover, age differences in socialization experiences vary across cultures. In this study, Tarong children's access to companions did not change dramatically between younger and older children, particularly with regard to the age of companions. And likewise, there was not much of a difference between the prosocial behavior distribution of older and younger Tarong children. By contrast, the children of Orchard Town had a dramatically different ecological picture when it came to the companions they had available (Figure 1). With entry into school, they have more access to peers and less access to infants, for example. Similarly, the prosocial behaviors of the older age group reflected a dramatically higher distribution of prosocial behaviors towards other children. As such, examinations of the impact of context on children's behaviors can be richer when a broader range of contexts is available, as is the case when a multi-community sample is drawn.

Finally, this study represents one of the few investigations of prosocial behaviors in children's natural settings. Most studies employ self- or other-reports of behaviors, controlled experimental or contextually manipulated situations, or naturalistic investigations limited to just one setting (e.g., classroom). While these controlled environments and studies have contributed to the study of prosocial development by isolating variables of interest, naturalistic investigations provide more ecologically valid examinations of prosocial behaviors and its correlates.

\section{References}

Abramovitch, R., Corter, C., Pepler, D. J., \& Stanhope, L. (1986). Sibling and peer interaction: A final follow-up and a comparison. Child Development, 57, 217-229.

Andres, T. D., \& Ilada-Andres, P. B. (1987). Understanding the Filipino. Philippines: New Day. 
Barton, E. J., Olszewski, M. J., \& Madsen, J. J. (1979). The effects of adult presence on the prosocial behavior of preschool children. Child Behavior Therapy, 1, 271-286.

Besevegis, E., \& Lore, R. K. (1983). Effects of an adult's presence on the social behavior of preschool children. Aggressive Behavior, 9, 243-252.

Bigelow, B. J., Tesson, G., \& Lewko, J. H. (1992). The social rules that children use: Close friends, other friends, and "other kids" compared with parents, teachers, and siblings. International Journal of Behavioral Development, 15, 315-335.

Birch, L. L., \& Billman, J. (1986). Preschool children's food sharing with friends and acquaintances. Child Development, 57, 387-395.

Bornstein, M. H., Tamis-LeMonda, C. S., \& Tal, J. (1992). Maternal responsiveness to infants in three societies: The United States, France, and Japan. Child Development, 63, 808-821.

Braten, S. (1996). When toddlers provide care: Infants' companion space. Childhood, 3, 449-465.

De Guzman, M. R. T., Edwards, C. P., \& Carlo, G. (2005). Prosocial behaviors in context: A study of the Gikuyu children of Ngecha, Kenya. Journal of Applied Developmental Psychology, 26, 542-558.

Edwards, C. P. (1986). Another style of competence: The caregiving child. In A. Fogel \& G. F. Melson (Eds.), Origins of nurturance: Developmental, biological and cultural perspectives on caregiving (pp. 95-111). Hillsdale, NJ: Erlbaum.

Edwards, C. P. (1993). Behavioral sex differences in children of diverse cultures: The case of nurturance to infants. In M. E. Pereira and L. A. Fairbanks (Eds.), Juvenile Primates: Life history, development, and behavior (pp. 327-338). New York: Oxford University Press.

Edwards, C. P., de Guzman, M. R. T., Brown, J., \& Kumru, A. (2006). Children's social behaviors and peer interactions in diverse cultures. In X. Chen, D. French, \& B. Schneider (Eds.), Peer relationships in cultural context (pp. 23-51). Cambridge, MA: Cambridge University Press.

Edwards, C. P., Knoche, L., Aukrust, V., Kumru, A., \& Kim, M. (2003). Parental ethnotheories of child development: Looking beyond independence and individualism in American belief systems. In U. Kim, K. Yang, \& K. Hwang (Eds.), Indigenous and cultural psychology: Understanding people in context (pp. 141-162). New York: Springer.

Edwards, C. P., Kumru, A., de Guzman, M. R. T., Ha, Y. H., Brown, J., \& Carlo, G. (2007). Cultural context and parent/peer attachments in the development of prosocial behaviors. Paper presented at the biennial meeting of the Society for Research in Child Development, Boston, MA, March 2007.

Eisenberg, N. (1983). Children's differentiations among potential recipients of aid. Child Development, 54, 594-602.

Eisenberg, N. (1986). Altruistic emotion, cognition and behavior. Hillsdale, NJ: Erlbaum.

Eisenberg, N. (2004). Prosocial and moral development in the family. In T. A. Thorkildsen \& H. J. Walberg (Eds.), Nurturing morality (pp. 119-136). Hillsdale, NJ: Erlbaum.

Eisenberg, N., Fabes, R. A., \& Spinard, T. L. (2006). Prosocial development. In N. Eisenberg, W. Damon, \& R. M. Lerner (Eds.), Handbook of child psychology, Vol. 3: Social, emotional and personality development (6th ed., pp. 646-718). New York: Wiley.

Enriquez, V. G. (1992). From colonial to liberation psychology: The Philippine experience. Quezon City, Philippines: University of the Philippine Press.

Fabes, R. A., Eisenberg, N., Karbon, M., Troyer, D., \& Switzer, G. (1994). The relations of children's emotion regulation to their vicarious emotional responses and comforting behaviors. Child Development, 65, 1678-1693.

Farver, J. A. (1999). Activity settings analysis: A model for examining the role of culture in development. In A. Goncu (Ed.), Children's engagement in the world: Sociocultural perspectives (pp. 99-127). Cambridge, UK: Cambridge University Press.

Fischer, J. L., \& Fischer, A. (1966). The New Englanders of Orchard Town, U.S.A. New York: Wiley.

Iannotti, R. J. (1985). Naturalistic and structured assessments of prosocial behavior in preschool children: The influence of empathy and perspective taking. Developmental Psychology, 21, 46-55.

Jocano, F. L. (1969). Growing up in a Philippine barrio. New York: Holt, Rinehart, \& Winston.

Knight, G. P., \& Chao, C. (1991). Cooperative, competitive, and individualistic social values among 8- to 12 -year-old siblings, friends and acquaintances. Personality and Social Psychology Bulletin, 7, 201-211.

Knight, G. P., Cota, M. K., \& Bernal, M. E. (1993). The socialization of cooperative, competitive, and individualistic preferences among Mexican American children: The mediating role of ethnic identity. Hispanic Journal of Behavioral Sciences, 15, 291-309.

Larson, R. W., \& Verma, S. (1999). How children and adolescents spend time across the world: Work, play, and developmental opportunities. Psychological Bulletin, 125, 701-736.

Nydegger, W. P., \& Nydegger, C. (1966). Tarong, an Ilocos barrio in the Philippines. New York: Wiley.

Super, C. M., \& Harkness, S. (1999). The environment as culture in developmental research. In S. L. Friedman, \& T. D. Wachs (Eds.), Measuring environment across the life span: Emerging methods and concepts (pp. 279-323). Washington, DC: American Psychological Association.

Super, C. M., \& Harkness, S. (2002). Culture structures the environment for development. Human Development, 45, 270-274.

Suzuki, L. K., \& Greenfield, P. M. (2002). The construction of everyday sacrifice in Asian Americans and European Americans: The roles of ethnicity and acculturation. Cross-Cultural Research, 36, 200-228.

Tietjen, A. M. (1994). Supportive interactions in cultural context. In F. Nestmann \& K. Hurrelmann (Eds.), Social networks and social support in childhood and adolescence (pp. 395-408). Berlin: de Gruyter.

Webster, G. D. (2003). Prosocial behavior in families: Moderators of resource sharing. Journal of Experimental Social Psychology, 39, 644-652.

Whiting, B. B. (1983). The genesis of prosocial behavior. In D. L. Bridgeman (Ed.), The nature of prosocial development (pp. 221-242). New York: Academic Press.

Whiting, B. B., \& Edwards, C. P. (1988). Children of different worlds: The formation of social behavior. Cambridge, MA: Harvard University.

Whiting, B. B., \& Whiting, J. W. M. (1975). Children of six cultures: A psycho-cultural analysis. Cambridge, MA: Harvard University Press.

Whiting, J. W. M., Child, I. L., Lambert, W. W., Fischer, A. M., Fischer, J. L., Nydegger, C. et al. (1966). Six cultures series, Vol. 1: Field guide for a study of socialization. New York: Wiley.

Zahn-Waxler, C., Friedman, S. L., \& Cummings, E. M. (1983). Children's emotions and behaviors in response to infants' cries. Child Development, 54, 1522-1528. 